Reply

\title{
Reply to Comment on "Comparison of Cloud Cover Detection Algorithms on Sentinel-2 Images of the Amazon Tropical Forest"
}

\author{
Alber Hamersson Sanchez ${ }^{1, *++} \mathbb{D}$, Michelle Cristina A. Picoli ${ }^{2,+} \mathbb{D}$, Gilberto Camara ${ }^{2,+} \mathbb{D}$, Pedro R. Andrade ${ }^{1,+} \mathbb{D}$, \\ Michel Eustaquio D. Chaves ${ }^{3,+} \mathbb{D}$, Sarah Lechler ${ }^{4}$, Anderson R. Soares ${ }^{2} \mathbb{D}$, Rennan F. B. Marujo ${ }^{2} \mathbb{D}$, \\ Rolf Ezequiel O. Simões ${ }^{2} \mathbb{D}$, Karine R. Ferreira ${ }^{2}(\mathbb{D})$ and Gilberto R. Queiroz ${ }^{2} \mathbb{D}$ \\ 1 Earth System Science Center, National Institute for Space Research-INPE, São José dos Campos 12227-010, \\ Brazil; pedro.andrade@inpe.br \\ 2 Image Processing Division, National Institute for Space Research-INPE, São José dos Campos 12227-010, \\ Brazil; michelle.picoli@inpe.br (M.C.A.P.); gilberto.camara@inpe.br (G.C.); anderson.soares@inpe.br (A.R.S.); \\ renan.marujo@inpe.br (R.F.B.M.); rolf.simoes@inpe.br (R.E.O.S.); karine.ferreira@inpe.br (K.R.F.); \\ gilberto.queiroz@inpe.br (G.R.Q.) \\ 3 Remote Sensing Division, National Institute for Space Research—INPE, São José dos Campos 12227-010, \\ Brazil; michel.chaves@inpe.br \\ 4 Institute for Geoinformatics, University of Münster, 48149 Münster, Germany; s.lechler@uni-muenster.de \\ * Correspondence: alber.ipia@inpe.br; Tel.: +55-12-3208-7330 \\ + These authors contributed equally to this work.
}

Citation: Sanchez, A.; Picoli, M.C.A.; Camara, G.; Andrade, P.R.;

Chaves, M.; Lechler, S.; Soares, A.; Marujo, R.; Simoes, R.; Ferreira, K.; et al. Response to Comment on "Comparison of Cloud Cover Detection Algorithms on Sentinel-2 Images of the Amazon Tropical Forest". Remote Sens. 2021, 13, 1028. https://doi.org/10.3390/rs13051028

Received: 22 December 2020

Accepted: 20 February 2021

Published: 9 March 2021

Publisher's Note: MDPI stays neutral with regard to jurisdictional claims in published maps and institutional affiliations.

Copyright: (c) 2021 by the authors. Licensee MDPI, Basel, Switzerland. This article is an open access article distributed under the terms and conditions of the Creative Commons Attribution (CC BY) license (https:// creativecommons.org/licenses/by/ $4.0 /)$.

\begin{abstract}
In their comments about our paper, the authors remark on two issues regarding our results relating to the MACCS-ATCOR Joint Algorithm (MAJA). The first relates to the sub-optimal performance of this algorithm under the conditions of our tests, while the second corresponds to an error in our interpretation of MAJA's bit mask. To answer the first issue, we acknowledge MAJA's capacity to improve its performance as the number of images increases with time. However, in our paper, we used the images we had available at the time we wrote our paper. Regarding the second issue, we misread the MAJA's bit mask and mistakenly labelled shadows as clouds. We regret our error and here we present the updated tables and images. We corrected our estimation and, consequently, there is an increment in MAJA's accuracy in the detection of clouds and cloud shadows. However, these increments are not enough to change the conclusion of our original paper.
\end{abstract}

Keywords: remote sensing; Amazon forest; clouds; Sentinel-2; MAJA

In our paper [1], we compare four cloud detection algorithms for the Amazon forest using Sentinel images from October 2016 to November 2018. Three of the algorithms (Fmask4, s2cloudless, and Sen2Cor) identify clouds using only spacial features. On the other hand, MACCS-ATCOR Joint Algorithm (MAJA) uses time series of images for this purpose. We compared the results of the four algorithms using points collected and classified by experts on remote sensing.

In their comments, Hagolle and Colin [2] pointed to two issues in the method reported in our paper [1], both related to MAJA. The first issue is related to the sub-optimal performance due to the interval between successive observations. The second issue indicates a misinterpretation of MAJA's bit mask.

Concerning the first issue, it is noteworthy that in the experimental design, we delimited the evaluation period between October 2016 and November 2018. This period was the same used in the comparison of the evaluated cloud detection algorithms. We recognize that this temporal delimitation may have impacted the accuracy of MAJA, since its detection improves with the inclusion of more images observed over time, as demonstrated in the results presented in [2]. 
Regarding the second issue, we misread the MAJA's bit mask. We mistakenly took shadows for clouds. We apologise for our error. To fix this error, the MAJA column in Table 3 of our paper must be ignored and instead one should use Table 1 . To correctly interpret MAJA's cloud mask, please use Table 2. This is because of the bit structure used by MAJA.

Table 1. Updated version of Table 3 [1]. Label recoding of the detection algorithms.

\begin{tabular}{|c|c|c|c|}
\hline Expert Label & Fmask4 & s2cloudless & Sen2Cor \\
\hline Clear & $\begin{array}{l}0 \text { Clear land } \\
1 \text { Clear water } \\
3 \text { Snow }\end{array}$ & 0 Clear & $\begin{array}{l}4 \text { Vegetation } \\
5 \text { Non vegetated } \\
6 \text { Water } \\
11 \text { Snow }\end{array}$ \\
\hline Cloud & 4 Cloud & 1 Cloud & $\begin{array}{l}8 \text { Cloud medium probability } \\
9 \text { Cloud high probability } \\
10 \text { Thins cirrus }\end{array}$ \\
\hline Cloud shadow & 2 Cloud shadow & & $\begin{array}{l}2 \text { Dark area pixels } \\
3 \text { Cloud shadows }\end{array}$ \\
\hline Other & & & $\begin{array}{l}0 \text { No data } \\
1 \text { Saturated or defective } \\
7 \text { Unclassified }\end{array}$ \\
\hline
\end{tabular}

Table 2. Bit interpretation of the MACCS-ATCOR Joint Algorithm's (MAJA) cloud mask. Source [3].

\begin{tabular}{ll}
\hline Bit & Description \\
\hline 0 & All clouds except the thinnest and all shadows \\
1 & All clouds (except the thinnest) \\
2 & Cloud shadows cast by a detected cloud \\
3 & Cloud shadows cast by a cloud outside image \\
4 & Clouds detected via mono-temporal thresholds \\
5 & Clouds detected via multi-temporal thresholds \\
6 & Thinnest clouds \\
7 & High clouds detected by $1.38 \mu \mathrm{m}$ \\
\hline
\end{tabular}

Figure $1 \mathrm{~b}$ updates Figure $3 \mathrm{~d}$ in [1]. This new version clearly identifies cloud shadows for MAJA. On the other hand, Figure 1b in [2] shows larger clear areas than Figure 1b. This is probably due to the differences in the length of the time series used. Our experiment used almost three years of images, most of them from Sentinel-2A because Sentinel-2B came into operation in July 2017, while [2] used images of five years (from 2016 to 2020). We added Figure 1a only as a reference for the readers.

Because of the misinterpretation of MAJA's bit mask, MAJA's accuracy in identifying clouds and cloud shadows needs to be updated, while the accuracy of clear observation was not affected. We updated the accuracy reported on Tables 4 and 5 of our paper and now they are presented here in Tables 3 and 4, respectively.

Table 3 shows the updated accuracy of MAJA according to the cloud detection algorithms. After the correction, there is an increment of 0.02 in the overall accuracy of MAJA. Furthermore, Table 4 shows the accuracy of each Sentinel-2 tile. The increments range from 0.01 to 0.05 in overall accuracy by tile.

However, these updates do not change the conclusion in our original paper. 
a. Image

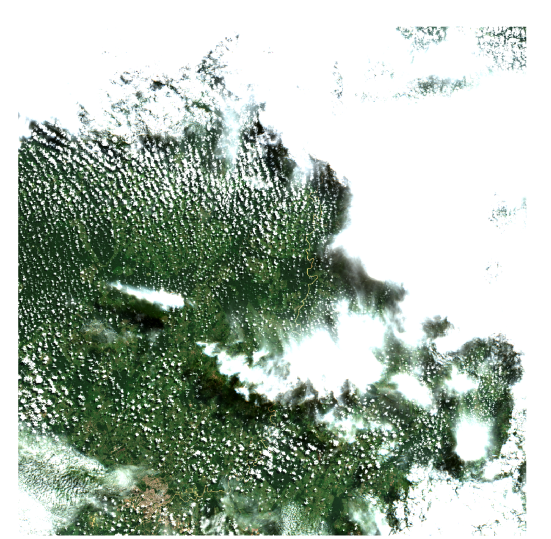

b. MAJA

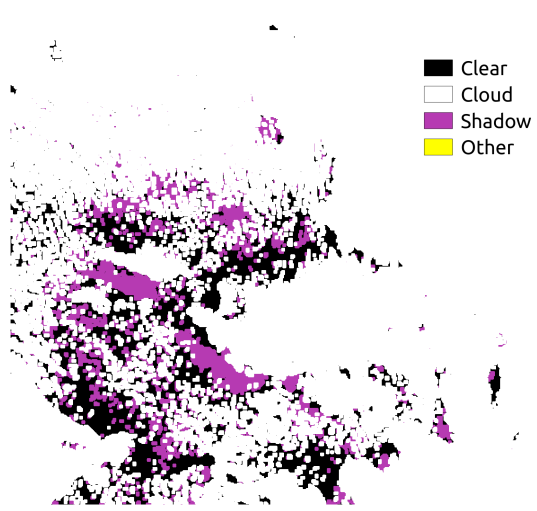

Figure 1. Updated Figure 3d [1]. Clouds detected on the Sentinel-2A image T19LFK of 7 May 2018. The color picture (a) uses bands 4, 3, and 2; (b) MAJA cloud mask.

Table 3. Updated version of Table 5 [1] with updated values of MAJA (in bold face). User and producer accuracies for each tile and cloud-detection algorithm.

\begin{tabular}{lccccccccccccc}
\hline & \multicolumn{3}{c}{ Fmask4 } & \multicolumn{3}{c}{ MAJA } & \multicolumn{3}{c}{ s2cloudless } & \multicolumn{3}{c}{ Sen2Cor } \\
\hline Label & F1 & User & prod & F1 & User & prod & F1 & User & Prod & F1 & User & prod \\
\hline Clear & 0.90 & 0.90 & 0.89 & 0.73 & 0.82 & 0.66 & 0.44 & 0.42 & 0.46 & 0.77 & 0.67 & 0.89 \\
Cloud & 0.94 & 0.91 & 0.96 & $\mathbf{0 . 8 0}$ & $\mathbf{0 . 6 9}$ & $\mathbf{0 . 9 6}$ & 0.66 & 0.59 & 0.75 & 0.89 & 0.90 & 0.88 \\
C. Shadow & 0.79 & 0.84 & 0.75 & $\mathbf{0 . 2 0}$ & $\mathbf{0 . 4 2}$ & $\mathbf{0 . 1 3}$ & & & 0.00 & 0.50 & 0.95 & 0.34 \\
\hline Overall & & 0.90 & & & $\mathbf{0 . 7 1}$ & & & 0.52 & & & 0.79 \\
\hline
\end{tabular}

Table 4. Updated version of Table 4 [1] with updated values of MAJA (in bold face). User and producer accuracies for each tile and cloud-detection algorithm.

\begin{tabular}{lllllllllllllll}
\hline & & \multicolumn{3}{c}{ Fmask4 } & \multicolumn{4}{c}{ MAJA } & \multicolumn{4}{c}{ s2cloudless } & \multicolumn{3}{c}{ Sen2Cor } \\
\hline Tile & Label & F1 & User & prod & F1 & User & prod & F1 & User & prod & F1 & User & prod \\
\hline \multirow{3}{*}{ T19LFK } & Clear & 0.83 & 0.81 & 0.86 & 0.66 & 0.69 & 0.63 & 0.47 & 0.31 & 0.94 & 0.66 & 0.52 & 0.92 \\
& Cloud & 0.96 & 0.96 & 0.96 & $\mathbf{0 . 9 2}$ & $\mathbf{0 . 8 7}$ & 0.97 & 0.77 & 0.94 & 0.66 & 0.94 & 0.96 & 0.92 \\
& C. Shadow & 0.68 & 0.71 & 0.66 & $\mathbf{0 . 1 5}$ & $\mathbf{0 . 4 0}$ & $\mathbf{0 . 1 0}$ & & & 0.00 & & & 0.00 \\
& Overall & & 0.92 & & & $\mathbf{0 . 8 3}$ & & & 0.64 & & & 0.84 & \\
\hline \multirow{2}{*}{ T20NPH } & Clear & 0.91 & 0.95 & 0.88 & 0.78 & 0.89 & 0.70 & 0.53 & 0.47 & 0.62 & 0.84 & 0.73 & 1.00 \\
& Cloud & 0.95 & 0.90 & 1.00 & $\mathbf{0 . 7 8}$ & $\mathbf{0 . 6 4}$ & $\mathbf{0 . 9 8}$ & 0.57 & 0.54 & 0.60 & 0.93 & 0.99 & 0.88 \\
& C. Shadow & 0.80 & 0.82 & 0.78 & $\mathbf{0 . 3 4}$ & $\mathbf{0 . 5 5}$ & $\mathbf{0 . 2 4}$ & & & 0.00 & 0.59 & 1.00 & 0.42 \\
& Overall & & 0.91 & & & $\mathbf{0 . 7 2}$ & & & 0.50 & & & 0.84 & \\
\hline \multirow{2}{*}{ T21LXH } & Clear & 0.88 & 0.82 & 0.95 & 0.80 & 0.89 & 0.72 & 0.35 & 0.33 & 0.36 & 0.78 & 0.64 & 0.99 \\
& Cloud & 0.94 & 0.96 & 0.92 & $\mathbf{0 . 8 0}$ & $\mathbf{0 . 6 7}$ & $\mathbf{0 . 9 8}$ & 0.60 & 0.52 & 0.70 & 0.91 & 0.99 & 0.83 \\
& C. Shadow & 0.81 & 0.89 & 0.75 & $\mathbf{0 . 1 7}$ & $\mathbf{0 . 4 9}$ & $\mathbf{0 . 1 0}$ & & & 0.00 & 0.58 & 0.98 & 0.41 \\
& Overall & & 0.90 & & & $\mathbf{0 . 7 3}$ & & & 0.45 & & & 0.81 & \\
\hline & Clear & 0.94 & 0.94 & 0.94 & 0.88 & 0.83 & 0.93 & 0.58 & 0.62 & 0.54 & 0.85 & 0.74 & 0.98 \\
& Cloud & 0.94 & 0.90 & 0.98 & $\mathbf{0 . 8 4}$ & $\mathbf{0 . 7 4}$ & 0.97 & 0.70 & 0.56 & 0.93 & 0.95 & 1.00 & 0.90 \\
& C. Shadow & 0.81 & 0.89 & 0.74 & $\mathbf{0 . 0 8}$ & $\mathbf{0 . 5 2}$ & $\mathbf{0 . 4 6}$ & & & 0.00 & 0.49 & 0.87 & 0.34 \\
& Overall & & 0.92 & & & $\mathbf{0 . 7 8}$ & & & 0.58 & & & 0.83 & \\
\hline & Clear & 0.87 & 0.95 & 0.80 & 0.42 & 0.70 & 0.30 & 0.23 & 0.34 & 0.18 & 0.63 & 0.64 & 0.63 \\
& Cloud & 0.87 & 0.79 & 0.96 & $\mathbf{0 . 6 3}$ & $\mathbf{0 . 4 8}$ & $\mathbf{0 . 9 1}$ & 0.61 & 0.46 & 0.94 & 0.71 & 0.62 & 0.83 \\
& C. Shadow & 0.80 & 0.82 & 0.77 & $\mathbf{0 . 2 2}$ & $\mathbf{0 . 3 0}$ & $\mathbf{0 . 1 7}$ & & & 0.00 & 0.53 & 0.97 & 0.36 \\
& Overall & & 0.86 & & & $\mathbf{0 . 5 1}$ & & & 0.43 & & & 0.65 & \\
\hline
\end{tabular}


Author Contributions: Conceptualization, A.H.S. and M.C.A.P.; methodology, M.C.A.P.; software, A.H.S., R.F.B.M., and S.L.; validation, A.H.S., A.R.S., M.E.D.C., M.C.A.P. and R.E.O.S.; formal analysis, A.H.S.; investigation, M.E.D.C., M.C.A.P.; resources and data curation, A.H.S.; writing-original draft preparation, A.H.S., A.R.S., M.E.D.C., M.C.A.P., S.L.; writing-review and editing, G.C., and P.R.A.; visualization, A.H.S., and M.C.A.P.; supervision, G.C., and P.R.A.; project administration, K.R.F. and G.R.Q.; funding acquisition, K.R.F. All authors have read and agreed to the published version of the manuscript.

Funding: This research was funded by the "Coordenação de Aperfeiçoamento de Pessoal de Nível Superior"-Brasil (CAPES)—Finance Code 001 (AS) and Process 88887.351470/2019-00 (M.E.D.C.), by the RESTORE+ project (PRA), which is part of the International Climate Initiative (IKI), supported by the Federal Ministry for the Environment, Nature Conservation and Nuclear Safety (BMU) based on a decision adopted by the German Bundestag, and by the Environmental Monitoring of Brazilian Biomes project (Brazil Data Cube), funded by the Amazon Fund through the financial collaboration of the Brazilian Development Bank (BNDES) and the Foundation for Science, Technology and Space Applications (FUNCATE), Process 17.2.0536.1 (ARS, AS, MP).

Institutional Review Board Statement: Not applicable.

Informed Consent Statement: Not applicable.

Data Availability Statement: Not applicable.

Conflicts of Interest: The authors declare no conflict of interest. The funders had no role in the design of the study; in the collection, analyses, or interpretation of data; in the writing of the manuscript, or in the decision to publish the results.

\section{References}

1. Sanchez, A.H.; Picoli, M.C.A.; Camara, G.; Andrade, P.R.; Chaves, M.E.D.; Lechler, S.; Soares, A.R.; Marujo, R.F.B.; Simões, R.E.O.; Ferreira, K.R.; et al. Comparison of Cloud Cover Detection Algorithms on Sentinel-2 Images of the Amazon Tropical Forest. Remote Sensing 2020, 12, 1284. [CrossRef]

2. Hagolle, O.; Colin, J. Comment on "Comparison of CloudCover Detection Algorithms on Sentinel-2 Images of the Amazon Tropical Forest". Remote Sensing 2021, 13, 1023. [CrossRef]

3. MAJA's Native Sentinel-2 Format. Available online: https://labo.obs-mip.fr/multitemp/sentinel-2/majas-native-sentinel-2format/\#English (accessed on 16 December 2020). 